\title{
A New Flexible and Economic Technology for the Low Pressure Sand Casting of Steel Alloys
}

\author{
Steven Krumm*, Nico Scheidhauer, Gotthard Wolf, Claudia Dommaschk \\ TU Bergakademie Freiberg, Foundry Institute, Bernhard-von-Cotta-Straße 4, 09599 Freiberg, Germany \\ ${ }^{*}$ e-mail: steven.krumm@gi.tu-freiberg.de
}

(C) 2021 Authors. This is an open access publication, which can be used, distributed and reproduced in any medium according to the Creative Commons CC-BY 4.0 License requiring that the original work has been properly cited.

Received: 23 June 2021/Accepted: 22 July 2021 / Published online: 26 August 2021.

This article is published with open access at AGH University of Science and Technology Press.

\begin{abstract}
Low pressure casting is a very well established process for the casting of aluminium alloys. In the field of ferrous materials, however, the process has so far only found a few applications. The crucial reasons for this are the low flexibility and poor economic efficiency of the existing technologies. Since 2016, a new technology has been developed at the Foundry Institute of the TU Bergakademie Freiberg, in which an induction crucible furnace can be used as a melting unit and, in combination with a cover including a casting pipe, as a casting unit. The new technology stands out from existing low-pressure casting technologies for ferrous materials, particularly in terms of its flexibility and cost-effectiveness. The main focus of the activities was the development of a casting pipe as well as the verification of its lifetime, the elaboration and verification of process parameters and sequences as well as the upscaling of the technology for an industrial application. In all considerations, the focus was on both the technical feasibility and the economic efficiency of the process. The result is extensive expertise that can be used in the future to offer a finished product for industrial applications as a plug-and-play solution together with an induction furnace construction company.
\end{abstract}

\section{Keywords:}

Low pressure counter gravity casting, steel, thin wall casting, casting pipe

\section{INTRODUCTION}

Low pressure casting is a process that is widely used in industry. To date, however, it has been used primarily with the material aluminium. There are many reasons for this fact. One of them is the fact that the flow velocities of the melt can be influenced and the turbulence of the flow can be kept low by a controlled and rising mould filling. This is of extraordinary importance for the casting of high-quality and safety-relevant components, which have to meet high standards with regard to the absence of defects. Low turbulence during mould filling prevents oxide skin entrapments and additional hydrogen absorption in aluminium alloys. For alloys with a high tendency to oxidation and gas absorption, these aspects are the main reasons for the use of the low pressure casting process [1-6].

However, for most steel alloys, these two points of argument do not apply to the same extent, and it is also possible to meet the quality requirements for the components with the gravity casting process. The advantages of the low pressure casting process, apart from the controlled and lower-turbulent mould filling, which apply in their entirety to both aluminium and steel materials, are counterbalanced by higher plant and operating costs for technologies currently available on the market. Additional advantages of the low pressure casting technology compared to gravity casting of steel alloys are often regarded as so called soft facts because their monetary effect cannot be obviously quantified. One example is the significantly higher process stability. This leads to tighter tolerance limits, lower casting temperatures, the potential to cast smaller wall thicknesses and to significantly reduce the reject rate while at the same time significantly increasing output [6].

Consequently, the higher plant and operating costs of a process that is not absolutely necessary are put against a process that has been established for many years in countless foundries. The question arises: why should a steel foundry invest in the technology of low pressure casting? The aim of a variety of investigations in recent years was to better quantify some of the soft facts in monetary terms. Next to that the focus was in particular on the development of a new technology for the low pressure casting of steel alloys with significantly lower plant and operating costs than the technologies available on the market so far. This article presents the developed technology in comparison to already existing systems and evaluates the economic aspects of some of the relevant soft facts. 


\section{THE PILOT PLANT AT THE FOUNDRY INSTITUTE FREIBERG}

At the end of 2017, a new vacuum induction furnace from the company Otto Junker was put into operation at the Foundry Institute of the TU Bergakademie Freiberg (TUBAF). The pilot plant can be used as a simple tiltable melting unit, whereby a special feature is that the melt can also be vacuum treated before tapping in order to remove dissolved gases. Figure 1 shows the furnace with the technical equipment for vacuum treatment.

a)

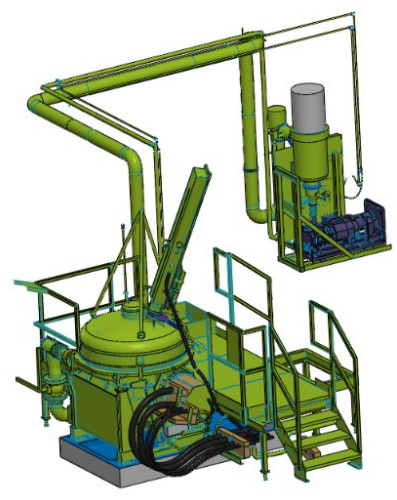

b)

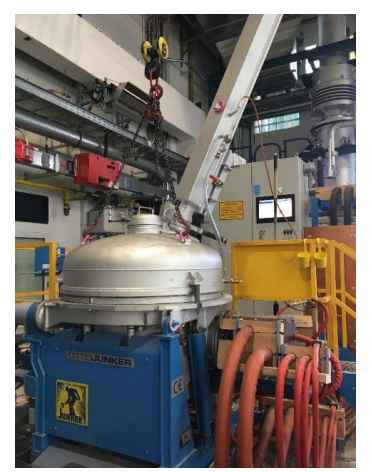

Fig. 1. Furnace with the technical equipment for vacuum treatment: a) 3D-CAD drawing of pilot plant induction furnace with vacuum process lid [7]; b) photo pilot plant induction furnace with vacuum process lid in foundry shop of TUBAF

The entire furnace can also be over pressurised by up to 1.5 bar when ready for casting. For this purpose, an additional pressure control system and a suitable furnace lid were developed. It only has a central opening at the top. Various preliminary tests in the technical centre of the Foundry Institute in Freiberg made it possible to design this opening as an enclosure including suitable sealing surfaces for a ceramic casting pipe suitable for the low pressure casting of steel. The complete structural design of a corresponding casting pipe geometry was already realised in advance at the Foundry Institute. In parallel, extensive tests were carried out with a wide variety of refractory materials, particularly with regard to their erosion and thermal shock resistance behaviour, in order to determine a suitable casting pipe material.

Since commissioning, the induction crucible furnace has been used, among other things, to develop the low pressure casting of steel in combination with a casting pipe. The pilot plant has a power output of $150 \mathrm{~kW}$ and can melt $300 \mathrm{~kg}$ of steel at a time. Figure 2 shows the furnace including the platform in the configuration with the low pressure casting lid on top and the casting pipe installed. On the lid there is a casting bed on which the sand mould is positioned and thus placed on the casting pipe. With this construction, it is possible to cast moulds with a diameter of $950 \mathrm{~mm}$. With $280 \mathrm{~kg}$, the majority of the melt volume can be used for the low pressure casting itself.

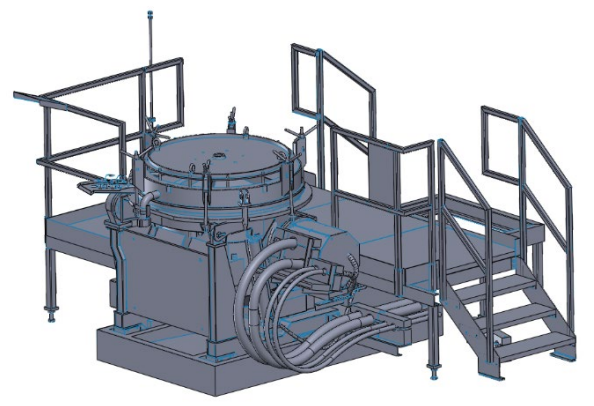

Fig. 2. Pilot plant induction furnace with low pressure casting lid [7]

Extensive test series were used to develop and optimise the technology of low pressure casting of steel with a crucible induction furnace in combination with a casting pipe for industrial use. The aim was to scale up the technology to enable series production on an industrial scale. The entire process of melting and casting was optimised in terms of procedures and adapted to the requirements of the foundry industry. Various parameters, which were determined through extensive series of tests, were incorporated into this development. These include, for example, the geometry and lifetime of the casting pipe and process sequences with regard to cycle time, which in turn fundamentally influences the design of a furnace system for industrial applications. Furthermore, all necessary parameters should be determined that allow a fundamental technological and monetary quantification of the advantage in comparison to counter gravity casting technologies already available on the market. Figure 3 shows the furnace system at the end of a casting batch. The low pressure casting lid is removed from the furnace with the built-in casting pipe to allow the charging of new material.

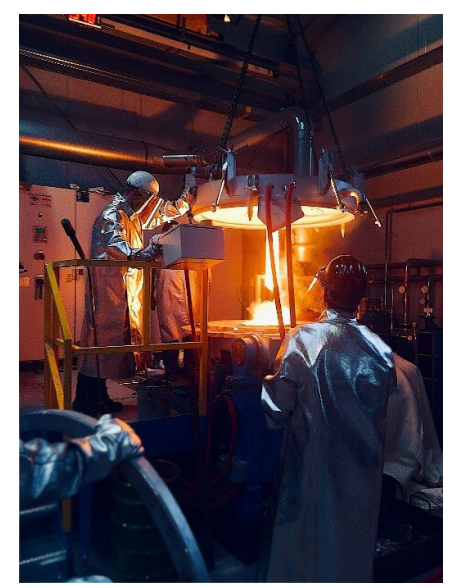

Fig. 3. Pilot plant induction furnace with lifted low pressure casting lid and casting pipe 


\section{COUNTER GRAVITY CASTING TECHNOLOGIES FOR STEEL ALLOYS}

The following Table 1 is intended to provide an overview of the essential features of two counter gravity casting processes established on the market as well as the newly developed one, and to enable a comparison of the technologies with classical gravity casting. Each feature in gravity casting is assumed to be neutral (0) and a relative evaluation is made for each of the mentioned processes. The three processes listed are all classified as counter gravity casting. Processes that operate in the pressure range above atmospheric pressure are more accurately referred to as low pressure counter gravity casting (LPCGC) processes, while systems that operate below atmospheric pressure are referred to vacuum counter gravity casting (VCGC) processes.

\subsection{Process control}

As shown in Table 1, all of the technologies listed offer equally clear advantages in terms of process control and mould filling characteristics compared to the gravity casting process. The positive evaluation of the process control results, for example, from the possibility of setting the pouring temperature and time very reproducibly for each pouring cycle. In the gravity casting process, the respective temperature changes constantly over a ladle journey. Moreover, in the case of stopper casting ladles, the existing pouring pressure and thus the volume flow and the flow velocity at the nozzle continue to decrease as the bath level falls.

\subsection{Mould filling characteristics and non-gas-porous}

The mould filling characteristics are very positive due to the upward movement and the fact that they can be controlled and monitored via a pressure curve.

The two systems working with overpressure are also characterised by a significantly reduced gas inclusion risk. This is mainly due to the mould filling characteristic, which is rising and very low in turbulence. The vacuum counter gravity casting process offers the same advantage with regard to gas inclusions, but also adds further risk for the same in the casted parts. Steel foundries in particular have naturally high scrap rates and low output due to the poor casting properties of the alloys. Both facts lead to a high recycling rate of the charged material. One consequence is a relatively high gas content in the melt. If the melt is filling the mould with the help of vacuum, it resembles a vacuum treatment of the melt in the mould. Especially if the melt is held in the mould until solidification with the help of the reduced atmospheric pressure, there is a greater risk of gas inclusions in the components. This effect can only be prevented by prior vacuum treatment or the use of decreased amounts of recycled material.

Table 1

Comparison of state of the art counter gravity casting technologies to gravity casting

\begin{tabular}{|c|c|c|c|}
\hline Technology & Vacuum counter gravity casting & $\begin{array}{l}\text { Existing low pressure } \\
\text { counter gravity casting }\end{array}$ & $\begin{array}{l}\text { NEW low pressure counter } \\
\text { gravity casting by TUBAF }\end{array}$ \\
\hline \multicolumn{4}{|l|}{ Illustration } \\
\hline & [8] & [9] & [7] \\
\hline Process control & +++ & +++ & +++ \\
\hline Mould filling characteristics & +++ & +++ & +++ \\
\hline Non-gas-porous & 0 & +++ & +++ \\
\hline Flexibility & 0 & --- & 0 \\
\hline Useable melt volume & --- & --- & - \\
\hline Charge changing & - & --- & 0 \\
\hline Availability & --- & -- & + \\
\hline Energy efficiency & + & -- & +++ \\
\hline Casting pressure & + & +++ & +++ \\
\hline Feeding effect & 0 & + & + \\
\hline Casting yield & ++ & +++ & +++ \\
\hline Cycle time & 0 & 0 & 0 \\
\hline Asset cost & --- & --- & - \\
\hline Cost of operation & --- & -- & + \\
\hline Cost per part & --- & -- & ++ \\
\hline $\begin{array}{l}\text { Evaluation compared to gravi } \\
+++ \text { much better; ++ better; + } \\
0 \text { - comparable } \\
\text {-- much worse; -- worse; - a li }\end{array}$ & $\begin{array}{l}\text { y casting: } \\
\text { a little better } \\
\text { tle worse }\end{array}$ & & \\
\hline
\end{tabular}




\subsection{Flexibility, useable melt volume and charge change}

In terms of flexibility, counter gravity casting technologies do not differ significantly from gravity casting. With regard to this aspect, only the low pressure casting process available on the market so far stands out negatively. The lack of flexibility is directly related to the useable melt volume. This is only approximately $50 \%$ of the capacity of the casting device, whereas it is above $90 \%$ in the process developed at the TUBAF. Consequently, it is much easier to change the alloy. The low pressure counter gravity casting device according to the state of the art usually has to be emptied at great expense for an alloy change. This process is very time consuming and thus reduces the availability of the system. In addition, a high proportion of recycled material is produced. With the newly developed low pressure casting process, a new batch can be directly assembled in the induction furnace in most cases. Only if the chemical analyses of the previous and next planned melt differ significantly does the small, non-pourable sump have to be removed.

\subsection{Availability}

The availability of the technologies differs significantly from each other. This is where the recently developed low pressure casting process stands out from the already established technologies. While casting often has to be interrupted in both vacuum counter gravity casting and existing low pressure casting systems, the new development enables almost uninterrupted casting. The reasons for the casting pauses in the established systems are, depending on the exact specific process design, an insufficiently long lifetime of the casting pipe or the necessity of recharging new material because the castable volume is exhausted. With the vacuum counter gravity casting process, it is possible to use single-use casting pipes that are automatically exchanged with each mould. The casting cycle itself can be designed quickly, but the resource efficiency is poor. In order to keep the operating costs moderate, especially due to the high consumption of casting pipes, these are very limited in their dimensions and only allow a low useable melt volume. This results in the need to frequently charge new melt into the casting device, which is associated with downtimes. This reduces availability. Alternatively, it is possible to use multiple use casting pipes. Current experience from the industry shows that only $4-5$ castings are possible before the casting pipe fails. This fact leads to additional downtimes for changing the casting pipe. In principle this could be avoided, because casting pipes with larger dimensions and a longer lifetime could be applied and still be cost-efficient. Similar long interruptions of the casting phases have to be planned for the low pressure casting technology currently available on the market. With an exemplary casting weight of $50 \mathrm{~kg}$ per mould and a cycle time of the entire casting cycle of $60 \mathrm{~s}$, a refilling process must take place approx. every $45 \mathrm{~min}$ for a useable melt volume of 2.25 to. This leads to a casting pause of approx. $15 \mathrm{~min}$ in each case. This process design already reduces the planned availability considerably. In this case, it reaches only $75 \%$.
The newly developed low pressure casting technology takes up the widely used layout of induction melting plants, which are particularly cost-efficient in a so-called tandem mode of operation. Two induction furnaces with the same capacity, positioned directly next to each other, work together as an operational unit. While one induction furnace keeps the melt at pouring temperature, pours and has above $90 \%$ of its capacity available as castable melt volume, in the second induction furnace the next batch is charged, melted and adjusted to the correct chemical composition. The specific power of the furnaces is selected in such a way that, depending on the maximum casting weight and the associated cycle time of the individual casting process, the second furnace has melted the batch ready for casting with buffer time before the first furnace has used up its castable melt volume. As soon as this is the case, the furnace lid with mounted casting pipe is lifted from the first furnace, which has been poured empty, onto the second furnace, which is ready to pour. The second induction furnace can now proceed directly with casting while the first induction furnace takes over the function of the melting unit. The process described starts all over again. The furnaces have merely changed their function. In this way, it is possible to increase the planned availability tremendously. With reference to the previously selected example of a casting weight of $50 \mathrm{~kg}$ and a cycle time of the casting cycle of $60 \mathrm{~s}$, only an interruption of the casting phase of approx. $3 \mathrm{~min}$ is necessary for the lid change every approx. $120 \mathrm{~min}$. This results in a planned availability of $97.5 \%$. Industrial processes are often evaluated on the basis of their OEE (overall equipment effectiveness). In the following, the influence of the different availabilities of the two low pressure casting technologies on this characteristic value will be clarified. Equation (1) [10] shows that the OEE results from the multiplication of availability, efficiency and quality.

$$
\text { OEE }=\text { Availability } \times \text { Efficiency } \times \text { Quality }
$$

With regard to the parameters of efficiency and quality, the two low pressure casting technologies do not differ fundamentally. Factors such as the general process structure, process control, the qualification of the employees and sometimes also maintenance management influence efficiency and quality far more than the difference in technology between the two processes themselves. For this reason, the same values are assumed for both processes. Half an hour of delay due to idling, short downtimes and reduced production speed per 8-hour shift as well as a reject rate of $10 \%$ are assumed as realistic values. This results in Equations (2) and (3):

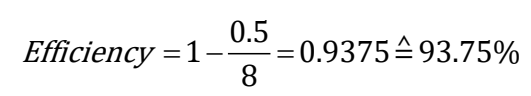

and

$$
\text { Quality }=1-0.1=0.9 \stackrel{\wedge}{=} 90 \%
$$


The OEE for the existing low pressure casting technology thus results as follows:

$$
O E E=0.75 \times 0.9375 \times 0.9=0.6328 \hat{=} 63.3 \%
$$

The OEE for the new low pressure casting technology by TUBAF results equivalent:

$$
O E E=0.975 \times 0.9375 \times 0.9=0.8226 \bumpeq 82.3 \%
$$

According to a generally accepted scale, an OEE below $65 \%$ means that the process is in need of major improvement. In this case, the top priority should be to analyse downtimes and stoppages. The range $65 \%$ to $85 \%$ represents the average of manufacturing operations, while an OEE above $85 \%$ is only achieved in processes that occupy a benchmark position. The OEE values calculated with certain assumptions for the two low pressure casting technologies thus illustrate on the one hand how unsuitable the low pressure casting system currently available on the market is from a production planning point of view and on the other hand that the newly developed technology has the potential to represent a benchmark process.

\subsection{Energy efficiency}

In terms of energy efficiency, all 3 counter gravity casting processes can stand out from conventional gravity casting processes. The reason for this is that the casting temperature can be set more precisely or within a narrower process window. In conventional gravity casting, 10 to 20 castings are usually made with one ladle, depending on the ladle size and casting weight. During this time, the melt cools down in the ladle. To prevent the last mould of a ladle to be cast from suffering cold runs, the first casting mould has to be casted much too hot. Depending on the process, in industrial practice this leads to an additional superheating of $40 \mathrm{~K}$ to $60 \mathrm{~K}$. This overheating is not necessary in the counter gravity casting process because each casting can be carried out with the minimum possible casting temperature. The melt can be kept constant within a very narrow tolerance window with the help of the furnace control. Numerous casting tests with the newly developed low pressure casting technology on a pilot plant scale at the Foundry Institute in Freiberg confirm that a temperature window of $\pm 8 \mathrm{~K}$ can be maintained in low pressure casting operation over a furnace journey. It can be assumed that this value can be reduced even further to $\pm 5 \mathrm{~K}$ in an industrial-scale plant. Besides the effect of energy efficiency, a precisely adjustable temperature also contributes to quality improvement. Higher casting temperatures at the beginning of a ladle cycle statistically lead to more shrinkage-related porosity, poorer surface finishes and gas porosity. The newly developed low pressure casting process is also characterised by the fact that the same unit is used for melting and casting. This eliminates the need for any transfer and transport processes. This leads to a significantly leaner internal logistical structure and also to savings in electrical energy. When tapping a furnace into a ladle, a temperature loss of $50 \mathrm{~K}$ to $70 \mathrm{~K}$ occurs on an industrial scale. In addition, a disproportionately large temperature loss of the melt in the furnace and a higher burn-off of volatile alloy elements occur simultaneously due to larger active surfaces during the tilting and pouring process. This again leads to higher energy and alloying agent costs. Figure 4 illustrates the required superheat of different casting technologies.

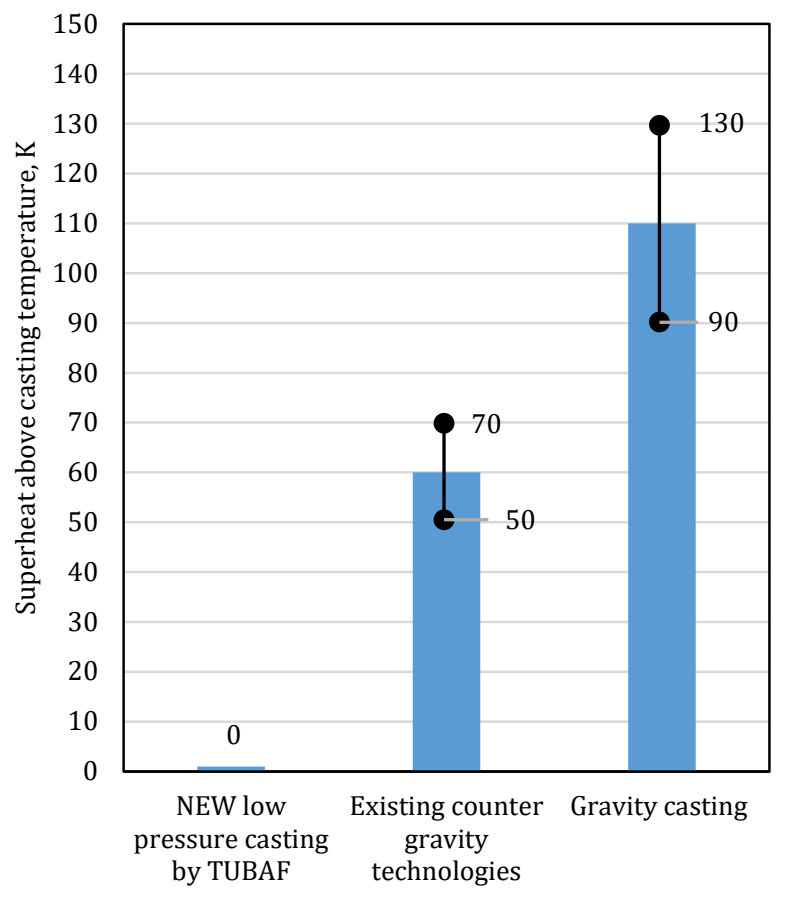

Fig. 4. Needed superheat average and range above casting temperature of different casting technologies

In the following, only the precisely quantifiable effect of the lower necessary superheating should be illustrated. If one compares the newly developed low pressure casting process with the conventional gravity casting process and also assumes a temperature window of $\pm 8 \mathrm{~K}$ or $\pm 5 \mathrm{~K}$ with the usual tolerance of the tapping temperature, then in total between $90 \mathrm{~K}$ and $130 \mathrm{~K}$ of superheating temperature can be saved. Modern induction furnaces require approx. $70 \mathrm{kWh}$ of energy per tonne of charge material for a superheat of $100 \mathrm{~K}$. If we again assume a casting weight of $50 \mathrm{~kg}$ per $60 \mathrm{~s}$ time window, a two-shift operation and the availability and efficiency already mentioned, the daily melt volume is approx. 43.9 tonnes. In this case, $50 \mathrm{~kg}$ cast weight in $60 \mathrm{~s}$ is also considered realistic for a gravity casting process, although the cycle time per mould is less than $60 \mathrm{~s}$, but less material can be cast per mould due to the realisable volume flows. The daily energy demand, which only arises due to the higher overheating in the gravity casting process compared to the newly developed low pressure casting process, is thus between approximately $2766 \mathrm{kWh}$ and $3995 \mathrm{kWh}$. Based on an electricity price of only $0.13 € / \mathrm{kWh}$, the necessary superheating in the gravity casting process alone means an additional daily financial expense of $360 €$ to $519 €$. With 250 working days, the annual additional expenditure can be 
estimated at around 90,000 € to $130,000 €$. Furthermore, as the ecological footprint of products gets more valuable these facts can lead to additional benefits in future.

As can be seen in Table 1, the existing low pressure casting system is rated worse than the gravity casting process in the overall evaluation of energy efficiency, despite the initially described advantages of a lower necessary superheat of $50 \mathrm{~K}$ to $70 \mathrm{~K}$. This is due to the fact that the existing systems are induction channel furnaces that are used as holding units. The special feature of these furnaces is the fact that they can only be operated with sump. In addition, the use of special refractory materials significantly extends the life of the wear lining around the channel inductor, because a new lining in these furnace areas is much more expensive than the relining of a crucible induction furnace, which is carried out once a week in most steel foundries. This means that the casting and holding furnaces of the low pressure casting technology currently available on the market are not switched off and have to keep a sump permanently warm. In total, this even consumes more energy compared to the gravity casting process than can be saved through the lower superheating.

\subsection{Casting pressure}

The casting pressure is rated positively compared to gravity casting for all counter gravity processes. This is mainly due to the fact that it is variable and more reproducible. Whereas in gravity casting it is strongly dependent on the current filling level of the ladle, any tilting movement that may take place and the mould geometry, in the counter gravity casting processes it is determined directly by the controlled pressure above or below the atmospheric pressure. A limitation in the vacuum counter gravity casting process is the fact that a smaller pressure range can be used for mould filling than in the low pressure casting process. The achievable pressure change compared to atmospheric pressure is naturally a maximum of approximately 1000 mbar, whereby it is technically very complex and cost-intensive to achieve such a low absolute pressure. In most cases, it can be assumed that a pressure difference of 650 mbar to 800 mbar can be used for mould filling. This limit can be significantly exceeded with low pressure casting processes. The limiting factors here are primarily the design and associated financial outlay. This effort must be matched by a concrete benefit so that pressure differences above 1500 mbar are meaningful. However, in furnaces with a very large capacity over 6 to, which are used at the same time for casting very large and especially high moulds (height $>1 \mathrm{~m}$ ), this is technically possible and physically not as limited as in vacuum counter gravity casting processes. The good reproducibility of the casting pressure with the newly developed low pressure casting technology could be proven in an overpressure range of up to $1500 \mathrm{mbar}$ in various pilot plant trials at the Foundry Institute. The following Figure 5 illustrates the percentage differences between the target pressure and the actual pressure in a total of 5 casting tests on different casting days with the same target pressure curve. In this case, the target pressure curve is divided into two sections, which first contain a constant pressure increase over $11 \mathrm{~s}$ and then a pressure hold over $14 \mathrm{~s}$.

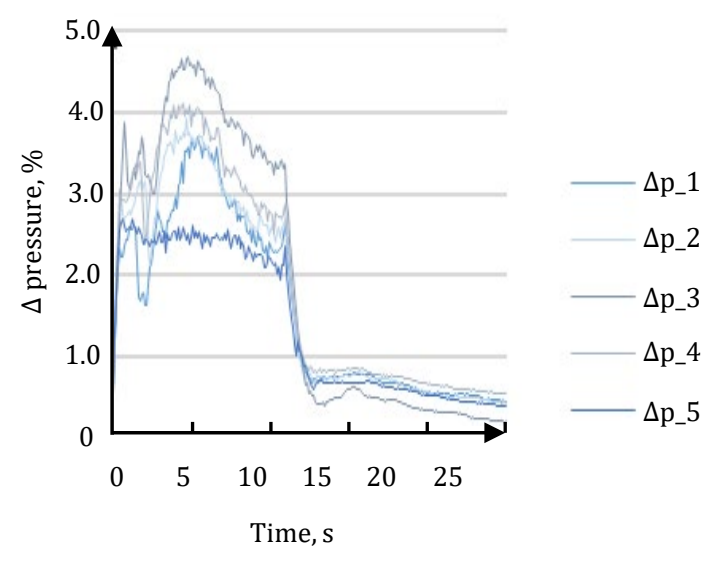

Fig. 5. Casting pressure difference target to current in low pressure casting pilot plant; $\Delta \mathrm{p}_{-} 1-\Delta \mathrm{p}_{-} 5$ - casting tests on different casting days with the same target pressure curve

It can be seen that the existing difference between the target and actual pressure occurs mainly shortly after the start of pressurisation. This can be explained by the control times of the valves. Within the first half second after the start of the pressure curve, the pneumatically controlled valves are opened first and thus the desired pressure increase cannot yet be achieved immediately. The actual pressure curve thus lags behind the target pressure curve by about $0.5 \mathrm{~s}$ over the entire first section of $11 \mathrm{~s}$. Despite this, there are only deviations of under $5 \%$ at any point in this first phase. If one neglects the initial delay of approximately $0.5 \mathrm{~s}$ and sets the time zero point of the actual pressure curve when there is a pressure increase in the system, then a more representative picture of the real deviation of the actual from the target pressure curve emerges. The corresponding percentage deviation is shown in Figure 6.

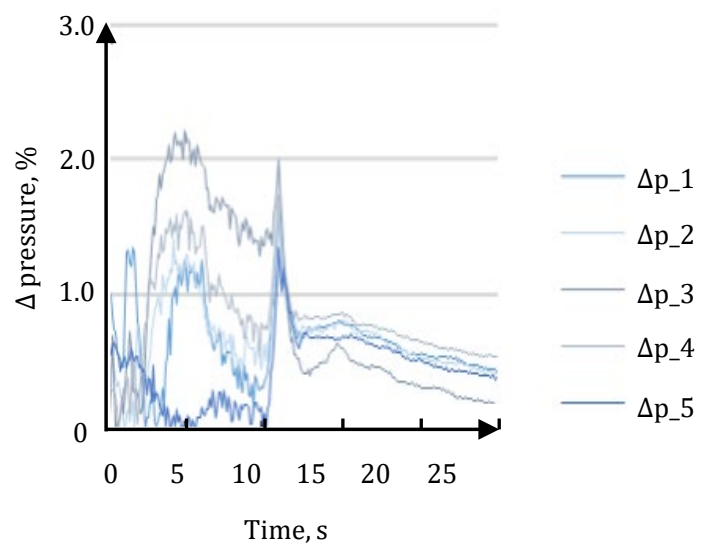

Fig. 6. Casting pressure difference target to current in low pressure casting pilot plant; synchronized; $\Delta \mathrm{p} \_1-\Delta \mathrm{p} \_5$ - casting tests on different casting days with the same target pressure curve

It is shown that in the phase of a linear pressure increase, there is only a deviation of approximately $2 \%$ between the target and actual pressure curves. In the pressure holding phase, this deviation is further reduced to lower than $1 \%$. At the time of the shift from phase 1 to phase 2 after $11 \mathrm{~s}$, the effect of the valve control can be seen again. The difference 
between the target and actual pressure curves increases briefly for a short period of time.

For a practical evaluation of the pressure deviations shown, the metallostatic pressure should be used. This results according to Equation (6):

$$
p=h \times g \times \rho
$$

where:

$$
\begin{aligned}
& p-\operatorname{pressure~}[\mathrm{Pa}], \\
& h-\operatorname{height}[\mathrm{m}], \\
& g-\operatorname{gravitational~constant~}[\mathrm{N} / \mathrm{kg}] \\
& \rho-\operatorname{density}\left[\mathrm{kg} / \mathrm{m}^{3}\right] .
\end{aligned}
$$

Extensive tests have shown that a maximum pressure deviation of 20 mbar or $2000 \mathrm{~Pa}$ can be assumed from one casting process to another. This results in a maximum changed metallostatic pressure height which is calculated as follows:

$$
h=\frac{p}{g \times \rho}=\frac{2000 \mathrm{~Pa}}{9.81 \mathrm{~N} / \mathrm{kg} \times 6800 \mathrm{~kg} / \mathrm{m}^{3}}=0.029 \mathrm{~m}
$$

If one compares this value with the usual bath level decrease in a stopper ladle, then one will notice that in industrial practice the casting pressure difference during a single casting process is usually greater than that which can be achieved in the low pressure casting process. This is realizable in a process-safe and permanent manner for each casting regardless of the furnace filling level. If one takes into account that the bath level in a stopper ladle often drops by $1 \mathrm{~m}$ to $2 \mathrm{~m}$ over a complete ladle cycle and thus over the course of approximately 10 to 20 castings, then it becomes clear how precisely the pressure control in the low pressure casting systems works.

These relationships also lead to the extremely good evaluation of the mould filling characteristics, as they result in very reproducible mould filling. Intensive tests on test specimens and real component geometries with the newly developed low pressure casting process have already proven this.

\subsection{Feeding effect and casting yield}

A general evaluation of the feeding effect compared to gravity casting is relatively difficult, as it depends very much on the component geometry that should be casted and thus to what extent an overpressure can be used for feeding after the mould has been filled completely. Furthermore, the design of the specific casting and gating system plays a very decisive role in this regard. At least the fact that it is possible to realise active feeding leads to the slightly positive evaluation of the two low pressure casting technologies. Since this form of active feeding is not possible with the vacuum counter gravity casting process, the evaluation compared to the gravity casting process is neutral.

Nevertheless, there is enormous potential to increase the casting yield with all counter gravity casting processes. For the two low pressure casting processes, this can be evaluated even better than for the vacuum counter gravity casting process for the last reason mentioned. The greatest potential for optimisation is offered by streamlining the casting and gating system. The flow paths can be kept significantly shorter in a mould designed for the counter gravity casting process. In addition, a larger number of components can usually be cast in one mould because significantly higher melt volume flows can be realised. In this way, the proportional mass of the casting system per component is reduced even further. Investigations with different component geometries have shown that the casting yield can be increased by $15 \%$ to $20 \%$ when switching from the gravity casting process to a low pressure casting process without extending the cycle time of the casting process per component. This increased casting yield has a large monetary impact, especially for high-alloyed steel castings. The pure material costs of high-alloyed $\mathrm{CrNi}$-steels are usually over $3.50 € / \mathrm{kg}$ and sometimes even exceed $6 € / \mathrm{kg}$. In concrete application cases, with a raw part weight of $3.8 \mathrm{~kg}$ and a material price of $4.75 € / \mathrm{kg}$, a reduction in manufacturing costs of more than $3.50 €$ per component could be demonstrated by increasing the casting yield alone, which corresponds to a reduction in the manufacturing costs of the raw part of more than $8 \%$.

\subsection{Cycle time}

The cycle time for all counter gravity casting processes is neutral compared to gravity casting. Depending on the exact process design and the design of the casting and gating system in the sand mould, both positive and negative effects are possible here. For this reason, no explicit evaluation will be made.

\subsection{Costs}

The final evaluation of the costs is largely based on all of the previous statements. In addition, especially in the evaluation of asset costs, there is the fact that with the counter gravity casting technologies already available on the market, a further unit is required for melting in addition to the casting unit, whereas with the newly developed low pressure casting process, melting and casting can take place in the same furnace. In the case of the vacuum counter gravity casting process, it should also be mentioned that the overall technical effort required to generate a vacuum in the casting system is greater than that required for casting with overpressure. This fact also leads to higher maintenance and servicing costs, which in particular is the cause of higher costs of operation compared to the low pressure casting processes.

\section{SUMMARY}

Overall, the higher asset costs, costs of operation, poor availability and other individual factors of the existing counter gravity casting processes leads to higher costs per casted component for the foundry. These could only be compensated by a reduction in the scrap rate due to higher process 
stability and, in particular, improved mould filling characteristics. However, the extent to which the scrap rate can be reduced in this way is highly dependent on the respective component, the explicit alloy and the quality requirements. For this reason, the technological decision was often made against a counter gravity casting process if this was not explicitly demanded by the customer or if the component could not only be produced using the counter gravity casting process due to its thin walls.

With the newly developed low pressure casting process, which uses a crucible induction furnace in combination with a casting pipe as a melting and casting unit, it is possible for the first time to reduce the manufacturing costs per component to the level of a gravity casting process or even to undercut them. This makes the low-pressure casting process interesting for industrial series production for the first time from an economic point of view. In addition, from a technological point of view, a highly reproducible and controllable process can be achieved. All in all, this leads to more narrowly definable process windows. In this way, the entire melting and casting process can be significantly optimised. For example, the potential is created to cast components with smaller wall thicknesses and to improve the quality or reduce the reject rate. Thus, the overall output can be increased and the costs per part can be reduced even further. In addition, completely new possibilities arise for the production of ultra-thin-walled cast steel components. The enormous variety of steel materials and their good specific properties, in combination with thin-walled and cost-efficient production using the newly developed low-pressure casting process, offer enormous potential for the development of new cast components. A major transformation is currently taking place particular in the automotive industry. New platforms for hybrid and electric vehicles have been developed and demand ever stiffer body structures with simultaneous requirements for weight reduction. In addition, this change also leads to the creation of completely new types of components. The newly developed low-pressure casting process has great potential, both from a technical and an economic point of view, to meet the changing market requirements and to competitively produce new types of high-performance components in best quality as cast components.

\section{REFERENCES}

[1] Herfurth K., Ketscher N. \& Kohler M. (2003). Gießereitechnik kompakt Werkstoffe, Verfahren, Anwendungen. Düsseldorf: Gießerei-Verlag.

[2] Drossel G., Friedrich S., Kammer C., Lehnert W., Thate W., Ullman M., Wenglorz H.-W. \& Zeltner S. (2009). Aluminium Taschenbuch 2: Umformung, Gießen, Oberflächenbehandlung, Recycling. Düsseldorf: Aluminium-Verlag.

[3] Niederdruck-Kokillengießen - ein Herstellungsverfahren für Leichtmetallgussteile mit besonders hohen Anforderungen an Festigkeit, Dehnung, Druckdichtheit und Schweißbarkeit. Retrieved from: https://www.guss.de/prozess/niederdruck-kokillen-giessen [4.03.2021].

[4] Niederdruck-Sandgießen - ein wirtschaftliches Verfahren für kleine und mittlere Seriengussteile sowie Prototypen. Retrieved from: https://www.guss.de/prozess/niederdruck-sandgiessen [11.03.2021]

[5] Campbell J. (2015). Counter Gravity Casting. In: Nastac L. et al. (Eds.), Advances in the Science and Engineering of Casting Solidification. Springer, Cham, 357-362. Doi: https://doi. org/10.1007/978-3-319-48117-3_42.

[6] Campbell J. (2012). Stop Pouring, Start Casting. International Journal of Metalcasting, 6, 7-18. Doi: https://doi.org/10.1007/ BF03355529.

[7] Otto Junker GmbH. (2017). Betriebsanleitung Ofenanlage MFT Ge 300 / 150 kW / 100-500 Hz - VAC Monomelt. Simmerath Lammersdorf: Otto Junker GmbH.

[8] Manufacturing - Casting Methods. Retrieved from: https:// www.european-aluminium.eu/media/1526/aam-manufacturing-1-casting-methods.pdf [5.03.2021].

[9] Gießofen für Niederdruckguss. Retrieved from: https://www.induga.de/pdf/PB-09_Niederdruck-Giessofen_web.pdf [5.03.2021].

[10] Focke M. \& Steinbeck J. (2018). Steigerung der Anlagenproduktivität durch OEE-Management. Wiesbaden: Springer Gäbler. 